\title{
Total respiratory impedance measured by means of the forced oscillation technique in subjects with and without respiratory complaints
}

\author{
H.G. Pasker, R. Schepers, J. Clément, K.P. Van de Woestijne
}

Total respiratory impedance measured by means of the forced oscillation technique in subjects with and without respiratory complaints. H.G. Pasker, R. Schepers, J. Clément, K.P. Van de Woestijne. (CERS Journals Ltd 1996.

ABSTRACT: The purpose of this study was to determine whether the forced oscillation technique is more sensitive than spirometry to detect lung function alterations in subjects with respiratory complaints.

The input impedance of the respiratory system (between 2 and $24 \mathrm{~Hz}$ ) and maximal expiratory flows and volumes were measured in 1,255 subjects referred for routine spirometry. A questionnaire concerning respiratory complaints was administered. A discriminant analysis was performed between subgroups of subjects without (137 males and 140 females), with moderate (115 males and 109 females) and with marked respiratory complaints (149 males and 132 females). A clear-cut separation was achieved by this analysis only between those subjects without and with marked complaints.

Both lung volumes and flows as well as impedance parameters (mean value and frequency dependence of resistance in females, mean resistance in males) contributed to the discrimination of subjects without and with marked respiratory complaints, although there was only a moderate decrease of discriminative power when the impedance parameters were excluded. The contribution of the forced oscillation parameters to discriminative power was larger in females than in males (40 vs $19 \%)$, which may be related to the higher prevalence of asthma in our population of females. Excluding the subjects with marked functional impairment improved the share of forced oscillation parameters only slightly with respect to lung volumes and flows (females $54 v$ s males 23\%). Considered separately, however, the sensitivity of spirometry and forced oscillation technique to detect symptomatic people appeared to be similar.

We conclude that impedance measurements by forced oscillation technique and routine spirometry are both associated with respiratory complaints. Our results indicate that the information provided by impedance measurements can be complimentary to that obtained by spirometric indices.

Eur Respir J., 1996, 9, 131-139.
Laboratorium voor Pneumologie, U.Z. Gasthuisberg, Leuven, Belgium.

Correspondence: K.P. Van de Woestijne Laboratorium voor Pneumologie

U.Z. Gasthuisberg

Herestraat 49

3000 Leuven

Belgium

\section{Keywords: Forced oscillation}

respiratory complaints

respiratory impedance

respiratory reactance

respiratory resistance

Received: November 301994

Accepted after revision September 51995

Supported by a grant from the European Community for Steel and Coal
The forced oscillation technique has been developed to study the impedance of the respiratory system. Although the technique has been available since 1956 [1], it is still not widely accepted in the routine lung function laboratories. One of the reasons for this is that the relevance of finding abnormal airway impedance values is unclear.

Previous studies have shown that in patients with upper airway obstruction [2], lower airway obstruction (asthma, chronic bronchitis and emphysema) [3], with restrictive lung disease due to diffuse interstitial lung disease or a stiff chest wall $[4,5]$ there is a uniform pattern of changes of resistance and reactance, i.e. an increase of respiratory system resistance $(R \mathrm{rs})$ at low oscillatory frequencies, a negative frequency dependence of $R$ rs and a decrease of respiratory system reactance $(X \mathrm{rs})$ at all frequencies between 2 and $32 \mathrm{~Hz}$. These changes probably reflect the increase of the influence of the upper airway shunt on the measurements, as a consequence of an increase of the impedance of the respiratory system [6-8], whatever its cause.

The lack of diagnostic specificity is a drawback of this technique. However, the technique might be useful if it were more sensitive than the conventional measurements of lung function. The technique might then be used as a nonspecific indicator, to detect incipient disorders of lung function. The purpose of the present study was to investigate, in a group of patients undergoing routine spirometry, whether the forced oscillation technique is more sensitive than spirometry to detect patients with respiratory complaints. 


\section{Materials and methods}

The forced oscillation data were collected with a computerized system developed by LÀNDSÉR and co-workers [9]. The patient was seated and breathing quietly via a screen pneumotachograph. A pseudorandom noise pressure signal, containing all harmonics of 2 to $24 \mathrm{~Hz}$, was applied at the mouth by means of a loudspeaker. To reduce the shunt effect of the upper airways the patient supported his/her cheeks with the hands.

Mouth pressure and airflow were recorded by identical differential transducers (Validyne MP45, $\pm 0.2 \mathrm{kPa}$ ). After analogue-to-digital conversion, the signal was analysed by a Fourier transform. The characteristics of the measuring device met the requirements of the technique as specified recently [10]. The accuracy of the measurements was checked by means of several reference impedances, the value of which had been measured by means of a wave tube [11]. A daily check of the calibration of the system was performed by one of these references. To eliminate the effect of breathing, the data were high-pass filtered (cut-off frequency $1 \mathrm{~Hz}$ ) and time averaged over $16 \mathrm{~s}$. Thus, the impedance of the respiratory system was calculated at $2,4,6, \ldots, 24 \mathrm{~Hz}$. The impedance $(Z r s)$ is divided into a real part or resistance $(R \mathrm{rs})$, in which flow is in phase with the pressure signal, and an imaginary part or reactance $(X \mathrm{rs})$, in which flow is $90^{\circ}$ out of phase with the pressure signal.

To express the amount of noise on the pressure and flow signal a coherence function was calculated at each frequency investigated. Only the data with a coherence function between 0.95 and 1.0 were retained. Because at frequencies below $6 \mathrm{~Hz}$ the coherence function was often below 0.95 , we considered only the data obtained between 6 to $24 \mathrm{~Hz}$. In each subject, at least three measurements were performed. The mean of the three measurements was used for further evaluation, a weight factor being applied for lacking data (in one or two of the three recordings).

Spirometry was measured with a heated pneumotachograph (Hans Rudolph, model 3813). The output signal of two pressure transducers (Validyne MP45 \pm 0.2 $\mathrm{kPa}$ ) coupled in parallel was digitized at a sampling rate of $125 \mathrm{~Hz}$, and calculation of volumes and airflows was performed with a personal computer and software developed in our laboratory. The system was calibrated twice daily with a $3 \mathrm{~L}$ calibration syringe. Each subject performed two slow expirations and at least three forced expirations until the acceptability and reproducibility criteria of the American Thoracic Society (ATS) were met or until a maximum of eight forced manoeuvres was reached [12]. In each subject, vital capacity (VC), forced expiratory volume in one second (FEV1) and maximal expiratory flow at 50\% actual VC (MEF50) were determined.

Each subject completed a standardized questionnaire with the help of a laboratory assistant, concerning the presence and intensity of respiratory complaints (cough, expectorations and shortness of breath), smoking habits, history of pulmonary or cardiac disease, and the use of pulmonary medication.

\section{Subjects}

From December 1992 to April 1994 we investigated 1,255 subjects who were submitted to routine spirometry in our lung function laboratory. In addition to the subjects with a definite pulmonary condition, many were referred for a general check-up, e.g. preoperative or preventive examinations. Most of the latter subjects had no particular respiratory complaints. For the present analysis, we compared three subgroups: subjects without any respiratory complaint (Group A, from now on referred to as "asymptomatic"); subjects with moderate and with marked respiratory complaints (Group B and Group C, referred to as "symptomatic"). People with a history of cardiac disease (124 males and 62 females) were excluded, to reduce the possibility that shortness of breath might be caused by a heart condition rather than by a pulmonary disease. The asymptomatic subjects with a history of pulmonary disease or using pulmonary medication were excluded. Smoking was not a criterion for exclusion. To be marked, respiratory complaints (cough, expectorations and/or shortness of breath) should have recurred at least every 2 months. Symptomatic subjects with a history of pulmonary disease or use of pulmonary medication were not excluded.

A discriminant analysis on complaints was performed, after exclusion of the outliers (see below), on 137 asymptomatic males versus 115 with moderate and 149 with marked complaints, and on 140 asymptomatic females versus 109 with moderate and 132 with marked complaints. Among the symptomatic subjects with marked complaints, the majority $(70 \%$ of the males and $65 \%$ of the females) suffered from obstructive lung disease (asthma, chronic bronchitis and emphysema). This percentage dropped to 29 and $35 \%$ in males and females, respectively, in the group with moderate complaints. Asthma was a more frequent diagnosis in females than in males: 35 versus $21 \%$ in the group with severe complaints. Biometric, spirometric and impedance parameters of the various groups are shown in tables 1 and 2 .

\section{Statistical analysis}

The statistical procedures were performed with the Statistical Analysis System (SAS) software package. To describe the impedance data, the method described by LÀNDSÉR and co-workers [13] was used: a fourth degree polynomial function was fitted through the resistancefrequency and the reactance-frequency curves of each individual:

$$
\operatorname{Rrs}(\text { or } X \mathrm{rs})=\mathrm{a} \cdot \mathrm{f}^{4}+\mathrm{b} \cdot \mathrm{f}^{3}+\mathrm{c} \cdot \mathrm{f}^{2}+\mathrm{d} \cdot \mathrm{f}+\mathrm{e}
$$

where $\mathrm{a}, \mathrm{b}, \mathrm{c}, \mathrm{d}$, e are constants and $\mathrm{f}$ the oscillatory frequency.

Each curve is then characterized by five, statistically independent parameters, i.e. the mean values of the resistance $(R \operatorname{rs}(0))$ and reactance $(X \mathrm{rs}(0))$ from 6 to $24 \mathrm{~Hz}$, the corresponding mean slope (first derivative: $\operatorname{Rrs}(1)$ and $X \mathrm{rs}(1)$ ), the mean curvature (second derivative: $R \mathrm{rs}(2)$ and $X \mathrm{rs}(2))$, and the mean third and fourth derivatives. Prediction values of $R \mathrm{rs}(0)$ to $R \operatorname{rs}(4)$ and of $X \mathrm{rs}(0)$ to $X \mathrm{rs}(4)$ were 
Table 1. - Biometric, spirometric and impedance parameters of the males investigated, after exclusion of the outliers (see text)

\begin{tabular}{|c|c|c|c|c|}
\hline & $\begin{array}{c}\text { Group A } \\
\text { Asymptomatic } \\
n=137\end{array}$ & $\begin{array}{c}\text { Group B } \\
\text { Moderate complaints } \\
\mathrm{n}=115\end{array}$ & $\begin{array}{c}\text { Group C } \\
\text { Marked complaints } \\
n=149\end{array}$ & $\begin{array}{c}\text { Duncan's } \\
\text { test }\end{array}$ \\
\hline Age yrs & $\begin{array}{c}53 \pm 14 \\
(21-83)\end{array}$ & $\begin{array}{c}56 \pm 15 \\
(19-82)\end{array}$ & $\begin{array}{c}55 \pm 16 \\
(18-87)\end{array}$ & $\begin{array}{c}A, B, C \\
p=0.20\end{array}$ \\
\hline Height $\mathrm{m}$ & $\begin{array}{c}1.75 \pm 0.06 \\
(1.58-1.90)\end{array}$ & $\begin{array}{c}1.73 \pm 0.07 \\
(1.56-1.90)\end{array}$ & $\begin{array}{c}1.72 \pm 0.07 \\
(1.56-1.88)\end{array}$ & $\begin{array}{c}A-B, C \\
p=0.003\end{array}$ \\
\hline Weight $\mathrm{kg}$ & $\begin{array}{r}76.3 \pm 11.9 \\
(50-110)\end{array}$ & $\begin{array}{r}74.2 \pm 12.1 \\
(46 \pm 110)\end{array}$ & $\begin{array}{r}75.2 \pm 12.3 \\
(49-110)\end{array}$ & $\begin{array}{c}\text { A, B, C } \\
p=0.37\end{array}$ \\
\hline VC $\%$ pred & $\begin{array}{c}100.0 \pm 11.4 \\
(74.3-127.7)\end{array}$ & $\begin{array}{c}92.8 \pm 15.2 \\
(37.1-125.6)\end{array}$ & $\begin{array}{c}89.2 \pm 17.3 \\
(44.8-133.9)\end{array}$ & $\begin{array}{l}A-B, C \\
p=0.0001\end{array}$ \\
\hline FEV1 \% pred & $\begin{array}{l}100.0 \pm 13.4 \\
(63.5-132.8)\end{array}$ & $\begin{array}{c}86.8 \pm 23.1 \\
(24.0-129.2)\end{array}$ & $\begin{array}{c}71.8 \pm 24.8 \\
(20.5-124.0)\end{array}$ & $\begin{array}{l}A-B-C \\
p=0.0001\end{array}$ \\
\hline FEV1/VC \% pred & $\begin{array}{l}100.0 \pm 7.6 \\
(80.1-116.5)\end{array}$ & $\begin{array}{c}92.5 \pm 16.9 \\
(36.4-116.0)\end{array}$ & $\begin{array}{c}79.4 \pm 19.8 \\
(32.5-121.6)\end{array}$ & $\begin{array}{l}A-B-C \\
p=0.0001\end{array}$ \\
\hline MEF50 \% pred & $\begin{array}{c}99.9 \pm 29.6 \\
(34.5-190.4)\end{array}$ & $\begin{array}{l}81.8 \pm 39.4 \\
(5.6-161.3)\end{array}$ & $\begin{array}{l}54.6 \pm 35.6 \\
(5.5-185.5)\end{array}$ & $\begin{array}{l}A-B-C \\
p=0.0001\end{array}$ \\
\hline $\operatorname{Rrs}(0) \quad \mathrm{kPa} \cdot \mathrm{L}^{-1} \cdot \mathrm{s}$ & $\begin{array}{c}0.253 \pm 0.052 \\
(0.149-0.396)\end{array}$ & $\begin{array}{c}0.291 \pm 0.087 \\
(0.151-0.597)\end{array}$ & $\begin{array}{c}0.345 \pm 0.101 \\
(0.151-0.752)\end{array}$ & $\begin{array}{l}A-B-C \\
p=0.0001\end{array}$ \\
\hline$R \mathrm{rs}(1) \mathrm{kPa} \cdot \mathrm{L}^{-1} \cdot \mathrm{s}^{2}$ & $\begin{array}{c}0.001 \pm 0.002 \\
(-0.005-0.005)\end{array}$ & $\begin{array}{c}-0.002 \pm 0.005 \\
(-0.019-0.005)\end{array}$ & $\begin{array}{c}-0.006 \pm 0.007 \\
(-0.047-0.005)\end{array}$ & $\begin{array}{l}A-B-C \\
p=0.0001\end{array}$ \\
\hline$X \mathrm{rs}(0) \mathrm{kPa} \cdot \mathrm{L}^{-1} \cdot \mathrm{s}$ & $\begin{array}{c}0.044 \pm 0.032 \\
(-0.045-0.127)\end{array}$ & $\begin{array}{c}0.002 \pm 0.082 \\
(-0.258-0.109)\end{array}$ & $\begin{array}{c}-0.060 \pm 0.111 \\
(-0.421-0.180)\end{array}$ & $\begin{array}{l}A-B-C \\
p=0.0001\end{array}$ \\
\hline
\end{tabular}

Values are presented as mean $\pm \mathrm{SD}$, and range in parenthesis. n: number of subjects; VC: vital capacity; FEV1: forced expiratory volume in one second; MEF50: maximal expiratory flow at 50\% VC; $\%$ pred: predicted according to the asymptomatic males of the present study; $\operatorname{Rrs}(0), X \mathrm{rs}(0)$ : mean resistance and reactance, respectively; $R \mathrm{rs}(1)$ : slope of the resistance-frequency curve. Duncan's multiple range test: dashes indicate significant difference between groups.

Table 2. - Biometric, spirometric and impedance parameters of the females investigated, after exclusion of the outliers (see text)

\begin{tabular}{|c|c|c|c|c|}
\hline & $\begin{array}{c}\text { Group A } \\
\text { Asymptomatic } \\
n=140\end{array}$ & $\begin{array}{c}\text { Group B } \\
\text { Moderate complaints } \\
\mathrm{n}=109\end{array}$ & $\begin{array}{c}\text { Group C } \\
\text { Marked complaints } \\
\mathrm{n}=132\end{array}$ & $\begin{array}{c}\text { Duncan's } \\
\text { test }\end{array}$ \\
\hline Age yrs & $\begin{array}{c}58 \pm 14 \\
(21-81)\end{array}$ & $\begin{array}{c}54 \pm 17 \\
(18-79)\end{array}$ & $\begin{array}{c}52 \pm 17 \\
(18-86)\end{array}$ & $\begin{array}{c}A-C \\
p=0.007\end{array}$ \\
\hline Height $\mathrm{m}$ & $\begin{array}{c}1.61 \pm 0.07 \\
(1.45-1.77)\end{array}$ & $\begin{array}{c}1.60 \pm 0.06 \\
(1.47-1.77)\end{array}$ & $\begin{array}{c}1.60 \pm 0.07 \\
(1.42-1.78)\end{array}$ & $\begin{array}{c}\text { A, B, C } \\
p=0.58\end{array}$ \\
\hline Weight $\mathrm{kg}$ & $\begin{array}{c}68.2 \pm 11.2 \\
(45-97)\end{array}$ & $\begin{array}{r}66.1 \pm 13.2 \\
(39-100)\end{array}$ & $\begin{array}{r}65.3 \pm 12.2 \\
(35-100)\end{array}$ & $\begin{array}{c}\mathrm{A}, \mathrm{B}, \mathrm{C} \\
\mathrm{p}=0.13\end{array}$ \\
\hline VC \% pred & $\begin{array}{l}100.0 \pm 12.2 \\
(72.0-133.1)\end{array}$ & $\begin{array}{c}94.6 \pm 16.3 \\
(55.4-142.5)\end{array}$ & $\begin{array}{c}87.4 \pm 17.6 \\
(24.5-132.7)\end{array}$ & $\begin{array}{l}A-B-C \\
p=0.0001\end{array}$ \\
\hline FEV $1 \%$ pred & $\begin{array}{l}100.0 \pm 12.4 \\
(68.1-129.9)\end{array}$ & $\begin{array}{c}91.1 \pm 19.8 \\
(33.1-129.5)\end{array}$ & $\begin{array}{c}78.2 \pm 20.5 \\
(25.7-112.9)\end{array}$ & $\begin{array}{l}A-B-C \\
p=0.0001\end{array}$ \\
\hline FEV1/VC \% pred & $\begin{array}{l}100.0 \pm 6.6 \\
(82.3-112.7)\end{array}$ & $\begin{array}{c}95.8 \pm 11.6 \\
(56.1 \pm 118.9)\end{array}$ & $\begin{array}{c}88.7 \pm 13.8 \\
(41.1-118.5)\end{array}$ & $\begin{array}{l}A-B-C \\
p=0.0001\end{array}$ \\
\hline MEF50 \% pred & $\begin{array}{l}100.0 \pm 25.3 \\
(47.1-166.3)\end{array}$ & $\begin{array}{l}83.1 \pm 39.3 \\
(8.0-198.2)\end{array}$ & $\begin{array}{l}61.7 \pm 30.5 \\
(5.5-132.1)\end{array}$ & $\begin{array}{l}A-B-C \\
p=0.0001\end{array}$ \\
\hline $\operatorname{Rrs}(0) \quad \mathrm{kPa} \cdot \mathrm{L}^{-1} \cdot \mathrm{s}$ & $\begin{array}{c}0.312 \pm 0.068 \\
(0.177-0.514)\end{array}$ & $\begin{array}{c}0.349 \pm 0.090 \\
(0.170-0.657)\end{array}$ & $\begin{array}{c}0.400 \pm 0.104 \\
(0.158-0.839)\end{array}$ & $\begin{array}{l}A-B-C \\
p=0.0001\end{array}$ \\
\hline $\operatorname{Rrs}(1) \mathrm{kPa} \cdot \mathrm{L}^{-1} \cdot \mathrm{s}^{2}$ & $\begin{array}{c}0.001 \pm 0.003 \\
(-0.007-0.008)\end{array}$ & $\begin{array}{c}-0.001 \pm 0.006 \\
(-0.022-0.014)\end{array}$ & $\begin{array}{c}-0.004 \pm 0.007 \\
(-0.036-0.007)\end{array}$ & $\begin{array}{l}A-B-C \\
p=0.0001\end{array}$ \\
\hline$X_{\mathrm{rs}}(0) \mathrm{kPa} \cdot \mathrm{L}^{-1} \cdot \mathrm{s}$ & $\begin{array}{c}0.037 \pm 0.049 \\
(-0.094-0.147)\end{array}$ & $\begin{array}{c}0.001 \pm 0.092 \\
(-0.291-0.176)\end{array}$ & $\begin{array}{c}-0.046 \pm 0.116 \\
(-0.527-0.135)\end{array}$ & $\begin{array}{l}A-B-C \\
p=0.0001\end{array}$ \\
\hline
\end{tabular}

Values are presented as mean $\pm \mathrm{SD}$, and range in parenthesis. \% pred: predicted according to the asymptomatic females of the present study. For further abbreviations see legend to table 1. 

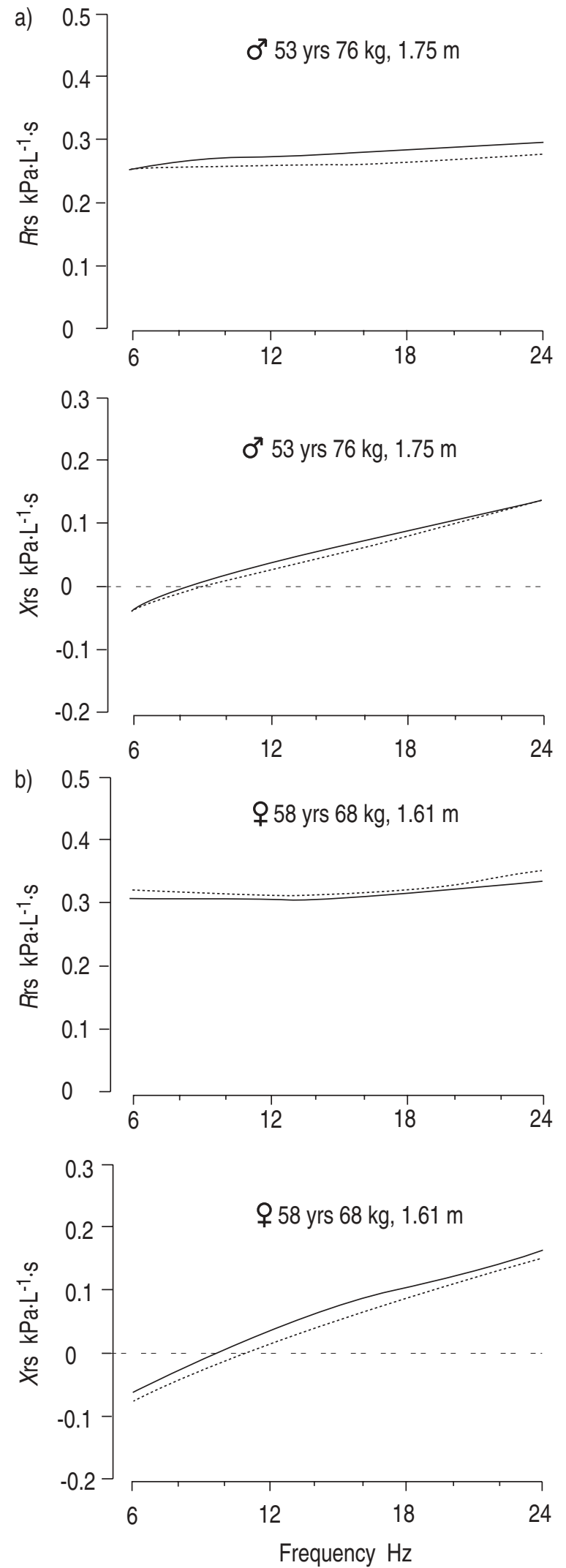

Fig. 1. - Comparison of examples of formerly published [14] and present prediction equations for $R \mathrm{rs}$ and $X_{\mathrm{rs}}$ versus frequency. $X_{\mathrm{rs}}$ and $R \mathrm{rs}$ $v s$ frequency curves for a) a man and b) a women with the average age, height and weight of the asymptomatic subjects investigated. Rrs: resistance of respiratory system; $X \mathrm{rs}$ reactance of respiratory system tance of respiratory system; $X \mathrm{rs}$ reactance of respiratory system
: prediction of PASKER et al. $[14] ; \cdots \cdots \cdots \cdots \cdot$ : current prediction. calculated by submitting each of these parameters obtained from the asymptomatic subjects to a multiple regression analysis as a function of sex, age, height and weight. Only those factors which had a significant influence on the predicted values were retained. The coefficients of the prediction equations for $\operatorname{Rrs}(0), \operatorname{Rrs}(1)$ and $X \mathrm{rs}(0)$ are given in Appendix I. In a previous study, we calculated prediction equations from a population consisting of healthy nonsmoking adults, recruited from outside the hospital [14]. The equations differ mainly on the fact that age was not included as a predictor. This is because the age span in the previous study was smaller than in the present population. Both prediction equations yield similar values for a subject with the mean age, height and weight of the groups investigated (fig. 1).

To prevent outliers from influencing the prediction equations of the asymptomatic group, the variables: age, weight, height, spirometric and impedance values (difference between predicted and measured value) were checked for extreme values. Subjects were excluded from the asymptomatic population if one of or more of these values departed by more than 3 standard deviations (SD) from the mean. This resulted in the exclusion of 34 males and 26 females.

In the symptomatic groups, subjects with an age, weight or height outside this range (mean of the asymptomatic subjects \pm 3 SD of the asymptomatic subjects) were also excluded from the discriminant analysis, to prevent the possibility that differences in the spirometry and impedance parameters would result from biometric differences between symptomatic and asymptomatic subjects. The values of VC and FEV1 of our asymptomatic subjects, especially of females, were markedly higher than the reference values of the European Community for Steel and Coal [15] (table 3). We therefore calculated our own prediction equations based on the spirometric values of the asymptomatic group (Appendix II). Figure 2 shows the distribution of the values of FEV1 (as percentage of predicted value) in the subjects without and with marked complaints. Canonical discriminant analysis between asymptomatic subjects and patients was performed with backward elimination of variables. Spirometry and airway impedance parameters were included in the full model. The variables were expressed as the difference between the measured and the predicted value: $\triangle \mathrm{VC}$, $\Delta \mathrm{FEV} 1, \Delta \mathrm{FEV} 1 / \mathrm{VC}, \Delta \mathrm{MEF} 50, \Delta R \mathrm{rs}(0), \Delta R \mathrm{rs}(1)$ and $\Delta X \mathrm{rs}(0)$. Only those variables which were significant at a $5 \%$ level, were retained. The contribution of each variable to the discriminant function was determined by calculating the

Table 3. - Average of spirometry values as predicted according to QUANJER [15], in the three groups of subjects: Group A - asymptomatic; Group B - moderate complaints; Group C - marked complaints

\begin{tabular}{lccccc}
\hline Sex & Group & $\begin{array}{c}\text { VC } \\
\% \text { pred }\end{array}$ & $\begin{array}{c}\text { FEV1 } \\
\% \text { pred }\end{array}$ & $\begin{array}{c}\text { FEV1/VC } \\
\% \text { pred }\end{array}$ & $\begin{array}{c}\text { MEF50 } \\
\% \text { pred }\end{array}$ \\
\hline Males & A & 105 & 104 & 99 & 83 \\
& $\mathrm{~B}$ & 102 & 93 & 89 & 65 \\
Females & $\mathrm{C}$ & 94 & 75 & 79 & 46 \\
& $\mathrm{~A}$ & 115 & 114 & 103 & 90 \\
& $\mathrm{~B}$ & 113 & 105 & 96 & 73 \\
& $\mathrm{C}$ & 100 & 89 & 91 & 57 \\
\hline
\end{tabular}

For abbreviations see legend to table 1 . 

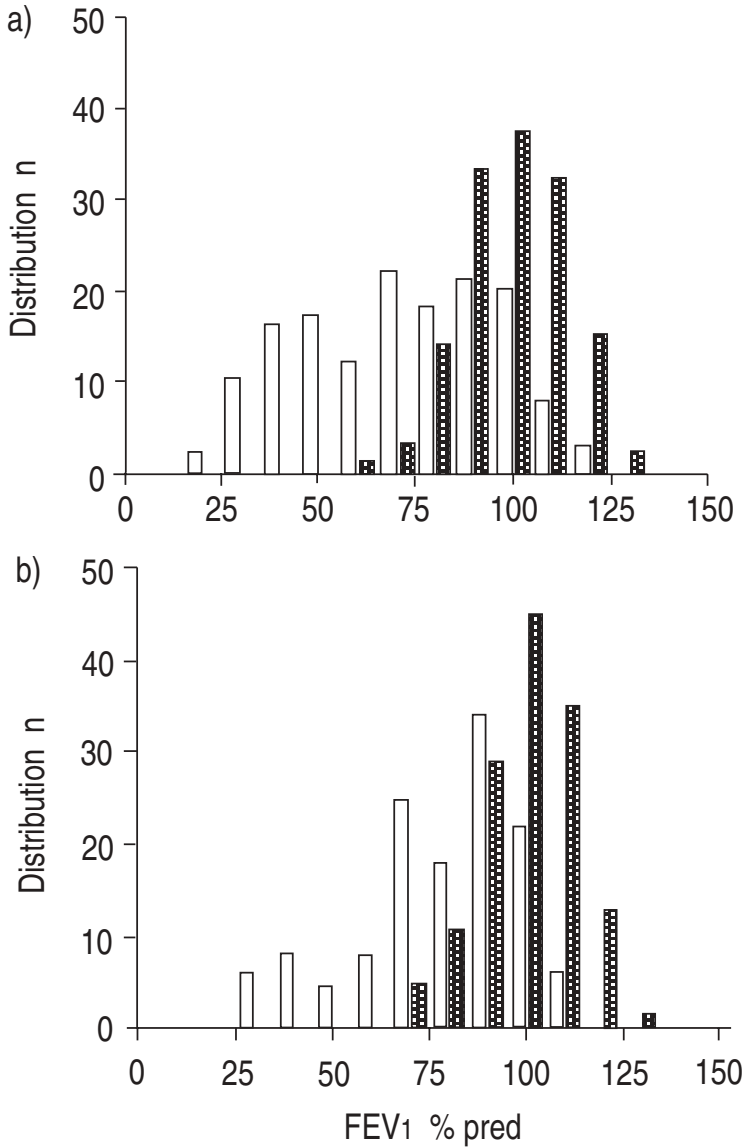

Fig. 2. - Distribution of the values of FEV1 (in \% of predicted value) in asymptomatic subjects and subjects with marked complaints: a) male; b) female. Class intervals of $10 \% . \quad \square$ : symptomatic; asymptomatic. FEV1: forced expiratory volume in one second.

standardized canonical coefficients and by comparing the ratio of each coefficient to the sum of the absolute values of these coefficients.

In subjects with strongly reduced spirometric values, the forced oscillation technique yields abnormal values but does not give additional information to detect a pathological condition: the spirometric values are sufficient to classify a subject as a patient [16]. Therefore, a discriminant analysis was repeated after exclusion of the subjects with a marked functional impairment. We chose to delete all subjects with a FEV $1<70 \%$ pred. This limit is approximately that of the lowest FEV1 values found in asymptomatic subjects (fig. 2).

\section{Results}

The comparison of the mean values of spirometry and forced oscillation parameters showed a progressive deterioration with severity of complaints: VC, FEV1, MEF50, $X \mathrm{rs}(0)$ decreased, $R \mathrm{rs}(0)$ increased, and the frequency dependency of resistance became negative. The differences between asymptomatic subjects (Group A), and patients with moderate (Group B) and marked complaints (Group C) were statistically significant (tables 1 and 2). The average resistance and reactance versus frequency curves of the asymptomatic subjects and of the group with marked complaints are presented in figure 3. A
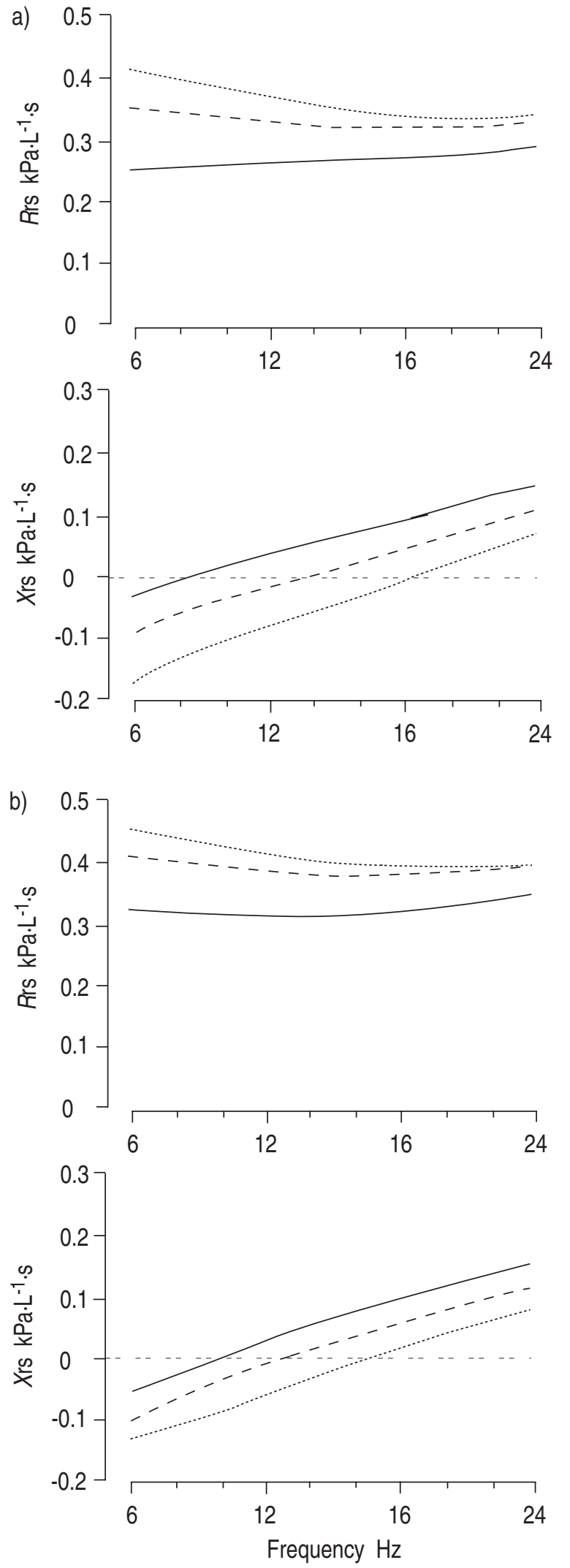

Fig. 3. - Average $R \mathrm{rs}$ and $X \mathrm{rs}$ versus frequency curves of asymptomatic subjects, and subjects with marked complaints (all subjects and subjects with FEV $1 \geq 70 \%$ predicted). a) males; b) females. Group A - asymptomatic; - - - : Group C - FEV $1 \geq 70 \%$ pred; ......... : Group C - all patients. For abbreviations see legends to figures 1 and 2 . 
canonical discriminant analysis between Groups A and $\mathrm{B}$ considering both spirometric and oscillation variables yielded values of $\mathrm{R}^{2}$ of 0.14 and 0.19 in males and females, respectively. This implied that the presence of complaints explained only $14-19 \%$ of the difference (variance) between the two groups. When only spirometry or forced oscillations were considered, $\mathrm{R}^{2}$ dropped to 0.10 and 0.13 , respectively, in males and to 0.16 and 0.10 , respectively, in females. Although these $\mathrm{R}^{2}$ values were still statistically significant, the overlapping of lung function variables between people with and without complaints was very large. The functional alterations were only loosely linked with complaints.

On the other hand, when the subjects of Group A were compared with those of Group $\mathrm{C}$, the discriminant analysis yielded higher values of $\mathrm{R}^{2}$ : 0.38 for both sexes (table 4). The variables retained by the analysis differed for men and women. The significant variables in males were $\triangle \mathrm{VC}, \Delta \mathrm{FEV} 1$ and $\Delta R \mathrm{rs}(0)$, and in females, $\triangle \mathrm{MEF} 50$, $\Delta R \mathrm{rs}(0)$ and $\Delta R \mathrm{rs}(1)(\triangle \mathrm{MEF} 50$ may be replaced by a combination of $\triangle \mathrm{VC}$ and $\triangle \mathrm{FEV} 1$ in females without loss of discriminant power; similarly, in the same group, $X \mathrm{rs}(0)$ may replace $R \operatorname{rs}(1)$; this is due to the tight correlation between the latter variables $\left(\mathrm{R}^{2}=0.92\right)$ ). Comparing spirometry and forced oscillation parameters, the spirometry parameters accounted for the major part of the discrimination (for approximately $81 \%$ in males and $60 \%$ in females). The impedance parameters accounted for the remaining $19 \%$ in males and $40 \%$ in females (table 4 ).

Table 4. - Relative contribution (\%) of the different variables in the discriminant function between asymptomatic subjects (Group A) and patients with marked complaints (Group C), when all patients were considered and when patients with marked functional impairment (FEV $1<70 \%$ pred) were excluded.

\begin{tabular}{cll} 
Males & & Females \\
All $\quad$ FEV $1>70 \%$ pred & All & FEV $1>70 \%$ pred \\
\hline
\end{tabular}

\begin{tabular}{lcccc}
\hline \multicolumn{5}{l}{ Spirometry and forced oscillations } \\
$\Delta \mathrm{VC}$ & $24 \%$ & $34 \%$ & -- & -- \\
$\Delta \mathrm{FEV} 1$ & $57 \%$ & $43 \%$ & -- & -- \\
$\Delta \mathrm{MEF} 50$ & -- & -- & $60 \%$ & $46 \%$ \\
$\Delta R \operatorname{rs}(0)$ & $19 \%$ & $23 \%$ & $20 \%$ & $26 \%$ \\
$\Delta R \operatorname{rs}(1)$ & -- & -- & $20 \%$ & $28 \%$ \\
$\mathrm{R}^{2}$ & 0.38 & 0.23 & 0.38 & 0.31 \\
Spirometry & only & & & \\
$\Delta \mathrm{VC}$ & $27 \%$ & $39 \%$ & -- & -- \\
$\Delta \mathrm{FEV} 1$ & $73 \%$ & $61 \%$ & $38 \%$ & $43 \%$ \\
$\Delta \mathrm{MEF} 50$ & -- & -- & $62 \%$ & $57 \%$ \\
$\mathrm{R}^{2}$ & 0.35 & 0.18 & 0.36 & 0.26 \\
Forced oscillations only & & & \\
$\Delta R \operatorname{rs}(0)$ & $37 \%$ & $47 \%$ & $49 \%$ & $53 \%$ \\
$\Delta X \mathrm{rs}(0)$ & $63 \%$ & $53 \%$ & $51 \%$ & $47 \%$ \\
$\Delta R \operatorname{rs}(1)$ & -- & -- & -- & -- \\
$\mathrm{R}^{2}$ & 0.30 & 0.17 & 0.26 & 0.22 \\
\hline
\end{tabular}

--: absence of contribution of variable to discriminant function. $\Delta$ : difference between measured and predicted. For further abbreviations see legend to table 1 . ( $\triangle$ MEF50 may be replaced by a combination of $\triangle \mathrm{VC}$ and $\triangle \mathrm{FEV} 1$ in females without loss of discriminant power; similarly, in the same group., $X_{\mathrm{rs}}(0)$ may replace $R \operatorname{rs}(1)$; this is due to the tight correlation between the latter variables $\left(\mathrm{R}^{2}=0.92\right)$ ).
The discriminant functions could be used to calculate a score for each subject of Group A and C. This allowed estimation of the specificity and the sensitivity of the discriminant function. When the specificity of the function was set to $95 \%$ (only $5 \%$ of the asymptomatic subjects yielded an abnormal score) the sensitivity was $65 \%$ for males and $59 \%$ for females. This means that among the subjects of Group C, 65 and 59\% of males and females, respectively, would be diagnosed by the function. After exclusion of the 104 subjects with marked functional impairment (FEV1 $<70 \%$ pred), $\mathrm{R}^{2}$ decreased to 0.23 in males and 0.31 in females (table 4 ). The selected variables were the same. For a specificity of $95 \%$, the sensitivity was $43 \%$ for males and $44 \%$ for females. One would expect, if the forced oscillation parameters are better predictors of incipient disease than spirometry, that the spirometry variables would disappear or at least become less significant in the discriminant function when subjects with marked functional impairment were excluded. This is hardly the case: in males the spirometry parameters still accounted for $77 \%$, and in females for $46 \%$, of discriminative power.

When the calculations were repeated without the forced oscillation parameters, the values of $\mathrm{R}^{2}$ were but slightly affected (table 4). A sensitivity of $64 \%$ in males and $50 \%$ in females (specificity of $95 \%$ ) was obtained when all subjects were considered. Excluding the subjects with marked functional impairment (FEV1 $<70 \%$ pred) yielded a sensitivity of $34 \%$ for males, $33 \%$ for females. Alternatively, when only the forced oscillation parameters were used, a sensitivity of 64 and 52\% was found in males and females, respectively. It dropped to $37 \%$ in males, $32 \%$ in females when only subjects with FEV1 $>70 \%$ pred were considered.

\section{Discussion}

In the present study, we used as reference values for the impedance parameters and for spirometry the values measured in the asymptomatic subjects. Comparison of the impedance values of the latter subjects with those measured in a group of healthy nonsmokers, published previously, yielded similar values (fig. 1). For the spirometric data, we planned originally to use the prediction equations of QuANJER [15]. However, the measured values of $\mathrm{VC}$ and FEV1 were on average larger, especially in women, than those expected in a normal population (table 3). It is unlikely that our normal population was supernormal, since it consists of hospital patients (inand out-patients) and smokers were not excluded. The measuring device was calibrated regularly and, as far as the spirometric technique was concerned, the recommendations of the ATS [12] were followed. QuANJER [15] points out that there are marked discrepancies in predicted values between authors, possibly due to differences among the populations investigated. A generation effect may also play a role, since the reference values of QUANJER [15] are based on studies performed at least 15 yrs ago. A preliminary comment originating from the multicentre study of the European Respiratory Society 
on chronic obstructive pulmonary disease [17] similarly mentions that the average FEV1 of healthy individuals screened for that study is larger than predicted by the original ECSC equations [18].

To investigate the problem of the sensitivity of airway impedance, as compared to spirometry, to detect lung disease in an early stage, a long term follow-up study in a large number of subjects should be set up. Because of the difficulties of this approach, groups of subjects have been studied with a high prevalence of incipient lung disease. Several studies were performed comparing healthy smokers and nonsmokers.

Conflicting results were published: some authors found that the forced oscillation technique was a sensitive tool to detect smokers [19-21], whilst others suggested that this was not the case $[5,22]$. In occupational medicine, the forced oscillation technique was found to be useful in addition to spirometry to investigate subjects exposed to respiratory irritants $[23,24]$. In the present study, we compared the ability of spirometry and of the forced oscillation technique to discriminate between subjects with and without respiratory complaints. Indeed, it is probable that subjects with respiratory complaints are more likely to have or to develop lung function abnormalities than those who never had complaints.

Study of two groups of patients, with moderate and marked complaints respectively, showed that, with respect to asymptomatic subjects, the severity of the complaints was accompanied by a progressive deterioration in the values of spirometry and of forced oscillations. However, it was only when the complaints were marked that a discriminant function yielded a satisfactory separation between asymptomatic and symptomatic subjects. We treated males and females separately and found that in both sexes there was a significant contribution of the impedance parameters to the discriminant function, but that the contribution of spirometry was more important. Even when subjects with marked functional impairment were excluded, the spirometry parameters remained important for the separation of symptomatic and asymptomatic subjects. An earlier study performed in this laboratory by CLÉMENT et al. [16], in which healthy males were compared with symptomatic male patients showed that forced oscillation parameters alone were able to discriminate between subjects with and without respiratory complaints. The discrimination was best for chronic obstructive pulmonary disease (COPD) patients with a FEV1 value of less than $50 \%$ pred (all subjects were classified correctly, when the specificity of the test was set to $95 \%$ ), whereas only $53 \%$ of symptomatic males with a FEV1 $>50 \%$ pred were classified correctly. The present results are in keeping with those found by CLÉMENT et al. [16]: when we used the same group division and only forced oscillation parameters were entered into the discriminant function, an almost equal percentage of symptomatic males were classified correctly (52\% of males with FEV1 value $>50 \%$ pred). CLÉMENT et al. [16] observed a moderate improvement of sensitivity when FEV1 was added to the discriminant function, FEV1 contributing $18 \%$ to the function. The opposite procedure applied here of using spirometry parameters alone showed that the latter were able to discriminate between subjects with and without respiratory complaints and that adding the forced oscillation parameters to the discriminant function resulted in only limited improvement of the sensitivity of the function. In this case, among the impedance parameters, it was the average level of resistance which added most to the discriminative power both in males and females, the slope of resistance contributing significantly to the function only in females. CLÉMENT et al. [16] found that the slope of resistance and the average reactance discriminated better than the average resistance. We could not confirm this finding.

Among the subjects with marked complaints, a number had markedly reduced values of spirometry. Keeping the latter subjects for the discriminant function necessarily influences the results, since the subjects with clearly reduced lung function are very likely to have severe complaints. The latter subjects are not suited for the study of the relative sensitivity of spirometry and of the forced oscillation technique, since in the presence of advanced airway obstruction the spirometric and forced oscillation data are both abnormal [16]. One problem was to decide what criterion should be used to select symptomatic subjects comparable to asymptomatic ones. The distribution of the FEV1 values in the latter subjects showed that absence of complaints was observed in males and females down to an FEV1 value of approximately $70 \%$ pred. This limit was, thus, used for the selection of the group of patients. The corresponding limit for $\mathrm{FEV} 1 / \mathrm{VC}$ was about $80 \%$ pred. In this group with normal or minimally reduced FEV1, spirometry proved to be superior to the forced oscillations, when both techniques were used in combination, to discriminate between males with marked and without respiratory complaints (table 4). In females, spirometry and the forced oscillation technique contributed to the discriminant function to nearly the same extent. On the other hand, when spirometry and forced oscillation technique were used separately, the latter technique could replace spirometry without a marked loss of discriminative power. The forced oscillation technique might, thus, replace spirometry in the detection of incipient functional alterations, when spirometry is not applicable.

The fact that spirometry and the forced oscillation technique both contribute significantly to the discriminant function in separating subjects with and without complaints indicates that the two measurements yield independent information and may select out different subjects. This is illustrated by the analyses performed separately on spirometry and forced oscillations variables: among the 177 subjects with marked complaints and with FEV1 $\geq 70 \%$ pred, 90 were classified correctly as patients by the discriminant analyses: 30 on the basis both of spirometry and forced oscillations; 29 on the basis of spirometry alone; and 31 on the basis of forced oscillations alone. This might be explained, in part at least, by differences in sensitivity, for instance, to detect an obstruction at different levels in the bronchial tree. Even though most of our patients suffered from obstructive lung disease, it is known that in subjects with asthma, chronic bronchitis and emphysema, who have a comparable degree of 
airway obstruction, the forced oscillation parameters are most abnormal in subjects with asthma and chronic bronchitis [3]. This is in keeping with the results of WesseLING and Wouters [25], who found the impedance to be abnormal in $70 \%$ of subjects with chronic bronchitis in the presence of normal spirometry (FEV $1 \geq 70 \%$ pred), and of GovaERTs et al. [26], who found impedance to be normal in a group of subjects with early emphysema and with altered spirometry. Differences in prevalence in the type of obstructive lung disease (more asthma in our group of females than in males) probably explain the larger diagnostic importance of forced oscillations and of spirometry in females and males, respectively.

\section{Appendix I}

Prediction equations for the average resistance $(\operatorname{Rrs}(0))$, average reactance $\left(X_{\mathrm{rs}}(0)\right)$ and slope of resistance to frequency $(R \operatorname{rs}(1))$, and the residual standard deviation (RSD). $\mathrm{H}=$ height $(\mathrm{m}), \mathrm{W}=$ weight $(\mathrm{kg}), \mathrm{A}=$ age (yrs)

$R \mathrm{rs}(0)$ and $X \mathrm{rs}(0)$ in $\mathrm{kPa} \cdot \mathrm{s} \cdot \mathrm{L}^{-1}, R \operatorname{rs}(1)$ in $\mathrm{kPa} \cdot \mathrm{s}^{2} \cdot \mathrm{L}^{-1}$

\section{Male}

$$
\begin{aligned}
\operatorname{Rrs}(0)= & -0.2454 \cdot \mathrm{H}+0.001564 \cdot \mathrm{W}-0.00055 \cdot \mathrm{A}+0.5919 \\
& (\mathrm{RSD}=0.0493) \\
\operatorname{Rrs}(1)= & 0.00842 \cdot \mathrm{H}-0.000047 \cdot \mathrm{W}-0.000018 \cdot \mathrm{A}-0.0095 \\
& (\mathrm{RSD}=0.00197) \\
X \mathrm{rs}(0)= & 0.1479 \cdot \mathrm{H}-0.000402 \cdot \mathrm{W}-0.00022 \cdot \mathrm{A}-0.1721 \\
& (\mathrm{RSD}=0.0306) \\
\text { Female } & \\
\operatorname{Rrs}(0)= & -0.4300 \cdot \mathrm{H}+0.00165 \cdot \mathrm{W}-0.00070 \cdot \mathrm{A}+0.9312 \\
& (\mathrm{RSD}=0.0619) \\
\operatorname{Rrs}(1)= & 0.01176 \cdot \mathrm{H}-0.000106 \cdot \mathrm{W}-0.000045 \cdot \mathrm{A}-0.00817 \\
& (\mathrm{RSD}=0.00256) \\
\operatorname{Xrs}(0)= & 0.2487 \cdot \mathrm{H}-0.001700 \cdot \mathrm{W}-0.00053 \cdot \mathrm{A}-0.2158 \\
& (\mathrm{RSD}=0.0406)
\end{aligned}
$$

\section{Appendix II}

Prediction equations based on the asymptomatic subjects of the present study.

$\mathrm{H}=$ height (m), $\mathrm{A}=$ age (yrs), volumes in $\mathrm{L}$, flows in $\mathrm{L} \cdot \mathrm{s}^{-1}$, $\mathrm{FEV} 1 / \mathrm{VC}$ in $\%, \mathrm{RSD}=$ residual standard deviation

\section{Male}

$\begin{array}{ll}\mathrm{VC}=5.93 \cdot \mathrm{H}-0.022 \cdot \mathrm{A}-4.46 & \mathrm{RSD}=0.540 \\ \mathrm{FEV} 1=4.17 \cdot \mathrm{H}-0.027 \cdot \mathrm{A}-2.20 & \mathrm{RSD}=0.481 \\ \mathrm{FEV} 1 / \mathrm{VC}=88.04-0.21 \cdot \mathrm{A} & \mathrm{RSD}=5.78 \\ \mathrm{MEF} 50=3.10 \cdot \mathrm{H}-0.047 \cdot \mathrm{A}+0.95 & \mathrm{RSD}=1.124 \\ \text { Female } & \\ \mathrm{VC}=3.9 \cdot \mathrm{H}-0.023 \cdot \mathrm{A}-1.73 & \mathrm{RSD}=0.399 \\ \mathrm{FEV} 1=2.9 \cdot \mathrm{H}-0.025 \cdot \mathrm{A}-0.61 & \mathrm{RSD}=0.323 \\ \mathrm{FEV} 1 / \mathrm{VC}=90.59-0.18 \cdot \mathrm{A} & \mathrm{RSD}=5.27 \\ \mathrm{MEF} 50=2.96 \cdot \mathrm{H}-0.038 \cdot \mathrm{A}+0.74 & \mathrm{RSD}=0.816\end{array}$

\section{References}

1. DuBois AB, Brody AW, Lewis DH, Burgess BF Jr. Oscillation mechanics of lungs and chest in man. J Appl Physiol 1956; 8: 587-594.
2. Van Noord JA, Wellens W, Clarysse I, Cauberghs M, Van de Woestijne KP, Demedts M. Total respiratory resistance and reactance in patients with upper airway obstruction. Chest 1987; 92: 475-480.

3. Van Noord JA, Clément J, Van de Woestijne KP, Demedts M. Total respiratory resistance and reactance in patients with asthma, chronic bronchitis and emphysema. Am Rev Respir Dis 1991; 143: 922-927.

4. Van Noord JA, Clément J, Cauberghs M, Mertens I, Van de Woestijne KP, Demedts M. Total respiratory resistance and reactance in patients with diffuse interstitial lung disease. Eur Respir J 1989; 2: 846-852.

5. Van Noord JA, Cauberghs M, Van de Woestijne KP, Demedts M. Total respiratory resistance and reactance in ankylosing spondylitis and kyphoscoliosis. Eur Respir $J$ 1991; 4: 945-951.

6. Cauberghs M, Van de Woestijne KP. Effect of upper airway shunt and series properties on respiratory impedance measurements. J Appl Physiol 1989; 66: 2274-2279.

7. Michaelson ED, Grassman ED, Peters WR. Pulmonary mechanics by spectral analysis of forced random noise. J Clin Invest 1975; 56: 1210-1230.

8. Peslin R, Duvivier C, Gallina C, Cervantes P. Upper airway artifact in respiratory impedance measurements. Am Rev Respir Dis 1985; 132: 712-714.

9. Làndsér FJ, Nagels J, Demedts M, Billiet L, Van de Woestijne KP. A new method to determine frequency characteristics of the respiratory system. J Appl Physiol 1976; 41: 101-106.

10. Van de Woestijne KP, Desager KN, Duiverman EJ, Marchal F. Recommendations for measurement of respiratory impedance by means of the forced oscillation method. Eur Respir Rev 1994; 4: 235-237.

11. Franken H, Cauberghs M, Ringelhann A, Clément J, Van de Woestijne KP. Forced oscillation technique: comparison of two devices. J Appl Physiol 1985; 59: 1654-1659.

12. American Thoracic Society. Medical section of the American Lung Association. Standardization of spirometry - 1987 Update. Am Rev Respir Dis 1987; 136: 1285-1297.

13. Làndsér FJ, Clément $\mathrm{J}$, Van de Woestijne KP. Normal values of total respiratory resistance and reactance determined by forced oscillations: influence of smoking. Chest 1982; 81: 586-591.

14. Pasker HG, Mertens I, Clement J, Van de Woestijne KP. Normal values of total respiratory input resistance and reactance for adult men and women. Eur Respir Rev 1994; 4(19): 134-137.

15. Quanjer $\mathrm{PH}$, (ed). Standardized lung function testing: report working party "Standardization of lung function tests". European Coal and Steel Community, Luxembourg. Bull Eur Physiopathol Respir 1983; 19 (Suppl. 5): 22-27 and 49.

16. Clément J, Làndsér FJ, Van de Woestijne KP. Total resistance and reactance in patients with respiratory complaints with and without airway obstruction. Chest 1983; 83: 215-220.

17. Pauwels RA, Löfdahl CG, Pride NB, Postma DS, Laitinen LA, Ohlsson SV. European Respiratory Society study on chronic obstructive pulmonary disease (EUROSCOP): hypothesis and design. Eur Respir J 1992; 5: 1254-1261.

18. Gibson GJ. Standardised lung function testing (editorial). Eur Respir J 1993; 6: 155-157.

19. Brochard L, Pelle G, De Palmas J, et al. Density and frequency dependence of resistance in early airway obstruction. Am Rev Respir Dis 1987; 135: 579-584. 
20. Kjeldgaard JM, Hyde RW, Speers DM, Reichert WW. Frequency dependence of total respiratory resistance in early airway disease. Am Rev Respir Dis 1976; 114: 501-508.

21. Hayes DA, Pimmel RL, Fullton JM, Bromberg PA. Detection of respiratory mechanical dysfunction of forced random noise impedance parameters. Am Rev Respir Dis 1979; 120: 1095-1100.

22. Peslin R, Hannhart B, Pino J. Impédance mécanique thoraco-pulmonaire chez des sujets fumeurs et nonfumeurs. Bull Eur Physiopathol Respir 1981; 17: 93105.

23. Jorna THJM, Borm PJA, Wesseling G, Wouters EFM.
Application of the forced oscillation technique (FOT) in different occupational settings. Eur Respir Rev 1994; 4: 19, 155-158.

24. Pairon JC, Iwatsubo Y, Hubert C, et al. Measurement of bronchial responsiveness by forced oscillation technique in occupational epidemiology. Eur Respir J 1994; 7: 484-489.

25. Wesseling GJ, Wouters EFM. Analysis of respiratory impedance characteristics in chronic bronchitis. Respiration 1992; 59: 81-88

26. Govaerts E, Demedts M, Van de Woestijne KP. Total respiratory impedance and early emphysema. Eur Respir $J$ 1993; 6: 1181-1185. 